\title{
Research on the Present Situation of Aerobics Courses in Jiangxi Province and Its Countermeasures
}

\author{
Yan Zhou \\ Jiangxi Vocational of Industry \& Engineering, Jiangxi 337055, China
}

Keywords: calisthenics, Teaching status quo, Jiangxi province, survey.

\begin{abstract}
: calisthenics as one of the most popular sports programs in colleges and universities has been deeply loved by college students and has become a major means to cultivate students' lifelong physical awareness. The purpose of this study is mainly aimed at part of the teaching situation of aerobics course in universities in Jiangxi province were analyzed, and find out the problems existing in the teaching, including teaching concept, students' interest, teaching methods and contents, sports facilities, etc., puts forward the ways to solve these problems and Suggestions.
\end{abstract}

\section{Introduction}

Aerobics is the emerging of various kinds of sports, a project, it was based on the physical exercises of the means to physical fitness as the goal, the physical activity as the main content, by means of the creation, gymnastics and music and dance together, has the very high exercise value and ornamental value, can reflect modern people pursue self-perfection, smooth stretch and individual body and mind of beautiful pursuit.

Schools in Jiangxi province aerobics also vigorously, after years of development, in promoting the popularization of quality education, strengthening teacher training of the overall environment, some universities in Jiangxi province in the aspect of teaching theory and teaching practice to explore, the obvious achievements, as a new activity, aerobics inside the school won the rapid promotion and development. And as part of the teaching aerobics course is under the guidance of the life-long education, according to the teaching characteristics and the aesthetic rule, use creative methods to develop personalized teaching activities, and aerobics teaching art through teaching activities to reflect, can rise to cultivate the students' interest in learning, strengthen the body quality, form the good habit of lifelong love sports.

\section{Analysis of the present situation of calisthenics teachers}

The teacher is the hope of education, the national education reform and career development needs a teacher team with excellent style, good business quality, reasonable structure and stable development.

\subsection{Age structure}

According to investigation found that after the current calisthenics teachers, some universities in Jiangxi province over the age of 45 years of age or older teachers accounted for $19.05 \%$ of the total, and aged 30 to 44, accounted for the most, 52.38\%, and aged under 30 teachers accounted for $28.57 \%$. Therefore, the age of school aerobics teachers tend to be younger.

\subsection{Educational structure}

The teacher with a master's degree or above accounted for 38.09\%, and with a bachelor degree of teachers accounted for $47.62 \%, 14.29 \%$, and other qualifications, data shows, the object of study in aerobics teaching team, the overall degree is low, master degree or above accounted for the proportion of low, this will of course theory research and practice activities cause some degree of influence. 


\subsection{Title structure}

According to the actual survey, only $4.76 \%$ of the current teaching staff in the school of calisthenics are professed, and $19.05 \%$ of associate professors, compared with $33.33 \%$ and $42.86 \%$ respectively for lecturers and teaching assistants. This from the side shows that in the teaching of aerobics course, because of the shorter time, most of the courses are taught by young teachers, which is more in line with the requirements of the teaching profession.

\subsection{Special ability of teachers team}

In the teaching staff of aerobics, the main item of the university was $47.62 \%$, while the main item was $23.82 \%$ and $14.28 \%$ respectively. The proportion of teachers in the main category was $9.52 \%$, while the proportion of teachers in other main items was $4.76 \%$.

\section{Analysis of the current situation of aerobics courses}

\subsection{Aerobics teaching objectives}

The teaching objective is the teaching result that the teacher should achieve in this course, the teaching task is to achieve these goals and needs the specific thing to do. Through the understanding of the school aerobics curriculum development, aerobics teaching task basically has the following several aspects: improving the students' physical quality, master the skills and methods of the aerobics, shaping the correct posture, movement elegant skilled, flexibility of the joints and muscle elasticity was improved. And cultivate the ability of sentiment and self-innovation through actual activities.

\subsection{Evaluation and evaluation methods of aerobics}

Survey data show that some universities in Jiangxi province still based primarily on aerobics in aerobics test routines and create action as the main test content, on the choice of the test details, mainly grasp of the students' quality, action skills of examination, examination related to the theoretical knowledge about application, form is unitary, the completion of the inspection for the action is more, and after a course for students of less incremental comparison and evaluation, comprehensive evaluation for students is not high.

\subsection{Teaching mode and teaching method of aerobics course}

Part of Jiangxi province colleges and universities aerobics teaching mode of investigation and analysis, choose the cooperative teaching pattern proportion about $19 \%$, and use experience fun mode is about $11 \%$, choose the least proportion of traditional teaching mode, is about $2 \%$, the proportion of teaching mode, with the reform of college PE teaching mechanism, the traditional teaching pattern of decline, sports teaching more students as the main body, teacher as a new model of the main body.

\section{Analysis of student learning situation}

\subsection{Demand of students' teaching content of aerobics}

Through the survey of students, and students for the key to music theory knowledge, exercise, aerobics appreciation is more interested in theory course of study mainly let students has certain understanding to the aerobics, form the correct aesthetic view, preliminary aesthetic ability, make the students master the basic method of exercise, and the ability to aerobics exercise and aesthetic form a systematic and more accurate cognition, the content is not only the students focus on content, is also the important component of the course, teachers should pay more attention to.

\subsection{Analysis of students' attitude to aerobics and learning motivation}

In the surveyed students, about $23 \%$ of the students attitude towards didn't also like it very much, and feel like $27.05 \%$ of the students, both of which a total of 868 students, $50.06 \%$ of all students. 
Data shows that most of the students in aerobics is love, and willing to participate in learning and training, so the development of the aerobics exercise in the school had a very good foundation, sports consciousness has reached a higher level. The proportion of students who disliked and disliked was $18.97 \%$.

\subsection{Students studying aerobics disorder analysis}

For aerobics course learning state of mind, more than $35 \%$ of the students think that part of the action is difficult, worry about hard to complete the action in accordance with the standard requirements, about $22 \%$ of the students think jump aerobics no intrinsic motivation, in addition, there are 36\% students think that fear others laugh at your own actions, $19 \%$ of students choose not to jump aerobics alone.

\section{Analysis of influencing factors of aerobics teaching}

\subsection{Objective conditions}

Venues and facilities of the school conditions for calisthenics teaching also has a significant impact, as the basis and prerequisite for hardware, the school if you don't have flat space and simple music playback devices, it does not have the basic conditions of aerobics classes. Through analysis shows that part of the colleges and universities in Jiangxi province does not have perfect indoor space, some no plastic runway and cement, and even some schools lack of fixed sports venues, hardware facilities behind become the important obstacle factors influencing development of aerobics in Jiangxi province.

\subsection{Subjective conditions}

Some majors lack excellent teachers, and schools will be severely restricted when they choose to open courses. And the setting of the teaching content and study the choice of the length of time, if you can't meet the reasonable requirements of students, can inhibit on the formation of the students' interest in learning, make students difficulty concentrating upon the new content, most people might hold credit state of mind to complete the task, the right mindset will not affect the quality of aerobics teaching.

\subsection{Student factors}

The main factors of students are the differences in the students' own aerobics. The difference between physical condition and calisthenics will affect the course schedule and content selection. If the content is too big, difficult will make quite a number of students in learning are very demanding, and the content is too simple, and can make the foundation good students are not learning motivation, interest will fade away. Therefore, it is necessary to consider the students' physical condition and the influence of the original calisthenics technology on the selection and method of course content.

\section{Countermeasures for innovation of college aerobics courses in Jiangxi province}

(1) Change the traditional evaluation method, combine various evaluation methods to assess student achievement, stimulate and improve students' interest in aerobics. Combined with modern teaching methods, improve teaching effect.

(2) Strengthen the construction of teaching staff, professionalize the teaching team, provide more opportunities for professional skills training, and update the teachers' theories and knowledge.

(3) Strengthen the extracurricular practice teaching activities, and through the aerobics association to offer the aerobics training class to provide the training and selection mechanism for the aerobics school team.

(4) Strengthen the construction of site facilities to ensure the completion of high-quality aerobics teaching. 
(5) In Jiangxi province, the examination of aerobics courses should be developed in a diversified direction.

(6) The teaching content of calisthenics should be diversified to enhance students' interest in learning.

\section{References}

[1] Zhao Hua. A study on curriculum reform of education professional aerobics in universities [J]. Journal of Hebei sports institute, 2011 (3) 38-47

[2] Yin ZhiQiong. The study on the reorientation and characteristics of college aerobics courses in the background of sunshine sports [J]. Gansu technology, 2011 (2) 168-170

[3] Wu yong. Research and reflection on the setting of education professional aerobics class in China's general universities [J]. Xichang college, 2007, (1) 116-118.

[4] Song WenLi. Research on the setting and implementation strategies of aerobics class in higher education institutions in China in the new century [J]. Journal of Harbin institute of sport, 2009, (4): 62-66.

[5] Wang Mei Hong. The research on the status quo and countermeasures of aerobics in sports colleges [J]. Journal of education college, Sichuan, 2011, (9): 63-66. 